\title{
A Case of Ruptured Pseudomyxoma Revealed by an Occlusive Syndrome
}

Karam Aziz*, Abdelouhab El Marouni, Houssam Belghali, Ahmed Zerhouni, Tarik Souiki, Karim Ibn Majdoub Hassani, Imane Toughrai, Khalid Mazaz

Visceral Surgery Service, Hassan II University Hospital, Faculty of Medicine and Pharmacy of Fez, Sidi Mohamed Ben Abdullah University, Fez, Morocco

DOI: $10.36347 /$ simcr.2020.v08i02.004

| Received: 20.12.2019 | Accepted: 27.12.2019 | Published: 08.02.2020

*Corresponding author: Karam Aziz

\section{Abstract}

Peritoneal pseudomyxomas or "gelatinous diseases "of the peritoneum are rare diseases, defined by the abundant gelatinous substance in the abdomen secondary to ruptured appendicular mucinous lesion whose macroscopic cystic aspect is the mucocele. Histological analysis makes it possible to distinguish adenucinosis diffuse peritoneal, a relatively progressive benign form, malignant forms or peritoneal carcinomatosis Mucinous of very serious evolution. When diagnosed, the peritoneal pseudomyxoma is usually diffuse, scattered throughout the peritoneal cavity. Our observation presents a case of peritoneal pseudomyxoma, detected early with an appendicular mucocele ruptured and located at the dead end of Douglas.

Keywords: Pseudomyxomas mucocele Occlusive Syndrome.

Copyright @ 2020: This is an open-access article distributed under the terms of the Creative Commons Attribution license which permits unrestricted use, distribution, and reproduction in any medium for non-commercial use (NonCommercial, or CC-BY-NC) provided the original author and source are credited.

\section{INTRODUCTION}

Peritoneal pseudomyxomas is a rare disease due to thick gelatinous deposits in the peritoneal cavity, most of these deposits come from ruptured ovarian cysts or appendicular mucoceles

Our observation reports a particular clinical form: the pseudo-myxoma peritoneal revealed by an intestinal obstruction

\section{Case Report}

A 30-year-old female with no specific history was admitted to the emergency room with an occlusion evolving from more than five days with pain and abdominopelvic gravity

On examination: non-pyretic patient, in good general condition, with a distended abdomen and presence of an abdomino-pelvic mass. biological parameters were normal.

ASP: colonic distension with hydro-areal levels

We performed a CT SCAN which found a bulky abdominal mass occupying the quasi-totality of the abdomen and responsible for a ileal distension of upstream with intraperitoneal effusion of average abundance.
Operated patient with median approach; surgical exploration revealed the presence of a gelatinous tumor occupying the entire peritoneal cavity we proceed to a resection and an anastomosis

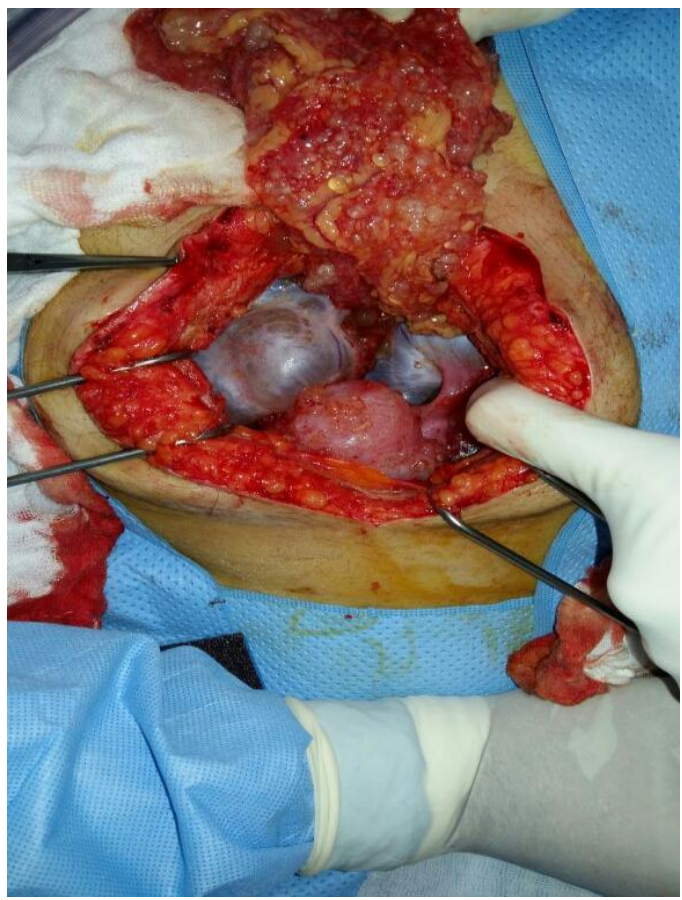

Fig-1: Image of the peritoneal pseudomyxoma 


\section{DISCUSSION}

The mucocele is defined by the distension of the appendicular lumen with mucin, without prejudging the nature of the lesion causal, benign (mucinous hyperplasia, inflammatory lesion or obstructive), precancerous (mucinous adenoma) or malignant (mucinous adenocarcinoma) [1]. In half of the cases, it revealed by chronic pain in the right iliac fossa. The table of acute appendicitis is rarer than for others appendicular tumors due to progressive obstruction light. More rarely, we find secondary pain invagination, torsion, or ureteral obstruction right. A mass can be palpated. The mucocele is found in $0.2-0.3 \%$ of appendectomies [1]. Its most complicated formidable is its rupture in the peritoneum ( 5 to $15 \%$ of cases): peritoneal pseudomyxoma. Pathology examination used to define the histological type of the appendicular lesion causal. Ruptured appendicular mucocele with extravasation mucus doesn't imply malignancy alone. The diagnosis of adenocarcinoma requires the presence of cellular marked numerous mitoses and a stromal reaction around cell clusters [2].

The radiological diagnosis must be evoked in front of an image cystic in the right iliac fossa [3]. In ultrasound, tubular and hypoechoic base. It can contain heterogeneous intraluminal particles hyperechoic depending on the consistency of the mucus. There is often associates fine curvilinear hyperechoic wall calcifications. Rarely, intra-cystic septa or formation endoluminal polypoid can be identified. On the scanner, it has a thick liquid density. His anatomical reports with the cecum are more obvious. Its walls are raised by the iodinated contrast agent. Wall calcifications are visible. The presence of a parietal nodular image of the mucocele is more in favor of an adenocarcinoma [4]. On the other hand, the infiltration of the periappendicular fat is non-specific and may be of inflammatory or neoplastic origin. A barrier at the base of the appendix as an inflammatory stenosis, a stercolite or tumor can be identified [5]. Its complications, type of inflammation, fuss, twist, or Right ureteral compression are clearly visible by these 2 methods.

The diagnosis of appendicular mucocele involves taking specific surgical load: special precautions are necessary during appendectomy to avoid rupture intraperitoneal which could be responsible for swarming and therefore of a peritoneal pseudomyxoma.

The prognosis of the disease is directly correlated to the histological type. Disseminated peritoneal adenomucinosis (PADD) relatively benign development is accompanied by superior survival, $80 \%$ at 10 years. Survival drops to less than $60 \%$ at 3 years for intermediate forms (CMP-I). For malignant forms peritoneal mucinous carcinomatosis (CMP), the course is extremely serious with less than $10 \%$ survival at 3 years [6].

\section{REFERENCES}

1. Dachman AH, Lichtenstein JE, Friedman AC. Mucocele of the appendix and pseudomyxoma peritonei. American journal of roentgenology. 1985 May 1;144(5):923-9.

2. Ronnett BM, Zahn CM, Kurman RJ, Kass ME, Sugarbaker PH, Shmookler BM. Disseminated peritoneal adenomucinosis and peritoneal mucinous carcinomatosis. A clinicopathologic analysis of 109 cases with emphasis on distinguishing pathologic features, site of origin, prognosis, and relationship to" pseudomyxoma peritonei". The American journal of surgical pathology. $1995 \mathrm{Dec} ; 19(12): 1390-408$.

3. Pickhardt PJ, Levy AD, Rohrmann Jr CA, Kende AI. Primary neoplasms of the appendix: radiologic spectrum of disease with pathologic correlation. Radiographics. 2003 May;23(3):645-62.

4. Kim SH, Lim HK, Lee WJ, Lim JH, Byun JY. Mucocele of the appendix: ultrasonographic and CT findings. Abdominal imaging. 1998 May 1;23(3):292-6.

5. Abdelouafi A, Essodegui F, Ousehal A, Kadiri R. Les mucocèles appendiculaires a propos de six cas. InAnnales de radiologie. Expansion scientifique publications. 1996; 39(3): 119-125

6. Ronnett BM, Zahn CM, Kurman RJ, Kass ME, Sugarbaker PH, Shmookler BM. Disseminated peritoneal adenomucinosis and peritoneal mucinous carcinomatosis. A clinicopathologic analysis of 109 cases with emphasis on distinguishing pathologic features, site of origin, prognosis, and relationship to" pseudomyxoma peritonei". The American journal of surgical pathology. 1995 Dec;19(12):1390-408. 